\title{
PRODUCTION OF SULFUR FROM GYPSUM AS AN INDUSTRIAL BY-PRODUCT
}

\author{
S. HILIGSMANN (1) *, S. DESWAEF (2), X. TAILLIEU (1), M. CRINE (2), N. MILANDE \\ (3) and PH. THONART (1)
}

(1) University of Liege, Centre Wallon de Biologie Industrielle. B40 Sart-Tilman. B-4000 LIEGE, BELGIUM. Phone : 32416628 61; fax : 3241662862

(2) University of Liege, Laboratoire de Génie Chimique. B6 Sart-Tilman. B-4000 LIEGE, BELGIUM. Phone : 32416635 61; fax : 3241663545

(3) Société Bertin, Centre de Bayonne. Zone Industrielle. F-40220 TARNOS, FRANCE. Phone : 33596486 48; fax : 3359649655

* Author to whom correspondence and reprint requests are to be addressed.

INDEX ENTRIES : gypsum, biodegradation, sulfate-reducing bacteria, sulfide, lactic acid, acetic acid, whey. 


\section{SUMMARY}

Biological sulfate-reduction was investigated at bench and pilot scale in order to determine optimum culture conditions.

Efficient strains of sulfate-reducing bacteria were selected by classical microbiological methods and by mutagenesis. Improvement factors including stripping, scale-up, sulfate and organic substrate concentrations have been studied in batch bioreactors .

Two types of pilot-scale bioreactors have been adopted, the first being completely mixed with free cells and the second having two stages with immobilized cells on a fixed bed.

An overall bioconversion capacity of $11 \mathrm{~kg} / \mathrm{m}^{3}$.day of gypsum and $1.2 \mathrm{~kg} / \mathrm{m}^{3}$.day of dissolved organic carbon has been achieved in the two-stage bioreactor.

\section{INTRODUCTION}

Gypsum $\left(\mathrm{CaSO}_{4} \cdot 2 \mathrm{H}_{2} \mathrm{O}\right)$ is produced by increasingly more industrial processes, for instance, when calcium carbonate or lime is used to neutralize sulfuric acid containing effluents or when apatite $\left(\mathrm{Ca}_{3}\left(\mathrm{PO}_{4}\right)_{2} \cdot \mathrm{CaF}_{2} \cdot \mathrm{CaCO}_{3}\right)$, the raw material used in phosphoric acid manufacture, is attacked by sulfuric acid.

The precipitated toxic metals which are often contained in this gypsum (mercury, lead, arsenic, zinc, cadmium, etc.) and the large amounts of gypsum produced (hundreds of millions of tons produced yearly throughout the world (1)) imply that there is, so far, no convenient method for its disposal without causing damage to the environment. Apart from some local opportunities such as its inclusion in plasters or in cements, gypsum (as industrial by-product) is usually disposed of in controlled sites or discharged in the seas, threatening to pollute soils and waters.

The biotechnological process reported here takes advantage of the so called dissimilatory sulfate-reducing bacteria (SRB) which can produce sulfide from sulfate and oxidize an organic substrate into carbonate $(2,3)$ according to :

$$
\mathrm{SO}_{4}^{2-}+\text { organic substrate } \varnothing \mathrm{S}^{2-}+\mathrm{CO}_{3}^{2-}
$$

The solid effluent, containing a majority of carbonate and impurities precipitated as 
sulfides, could be recycled repeatedly in neutralization in order to concentrate the toxic metals. Alternatively, the sulfide could be recycled in the manufacture of sulfuric acid, after chemical transformation into sulfur (derivatives of the Claus process using catalysts (4)).

Most of the available literature describes the reduction of highly soluble sodium or ammonium sulfate $(5,6)$ or the reduction of relatively low concentrations of $\mathrm{CaSO}_{4} \cdot 2 \mathrm{H}_{2} \mathrm{O}$ (slightly above the solubility threshold; $7,8,9,10$ ). However, preliminary experiments have shown a more efficient gypsum reduction at concentrations higher than the solubility threshold. Experiments would then have to cope with a multiple-phase culture medium. However, these sulfate reduction conditions have not been investigated in detail.

The purpose of this study (carried out by four research groups within the European Community, 11) was to investigate and improve a biotechnological process that could economically cope with the disposal of industrial gypsum and its relatively expensive chemical reduction which requires a great deal of energy (reaction of gypsum with coal at 700 to $1200{ }^{\circ} \mathrm{C}$ to form $\mathrm{CaO}, \mathrm{CO}_{2}$ and $\left.\mathrm{SO}_{2}(4)\right)$.

To achieve this objective, only cheap residual organic substrates from food or other industries were considered. Therefore, incompletely lactate-oxidizing sulfate-reducing bacteria (LSRB), which produce acetate, were chosen for study due to their fast and minimally restricted metabolism compared to other metabolic processes oxidizing organic substrates $(3,12,13,14)$. Nevertheless, they were combined with acidogenic bacteria in order to convert the raw residual organic substrate into the suitable electron donor for SRB (15).

Only complete Dissolved Organic Carbon (DOC) degradation - sulfate reduction processes were promoted, therefore another type of SRB was studied, the completely acetateoxidizing sulfate-reducing bacteria (ASRB), which is able to degrade acetate only to carbonate, with further reduction of gypsum $(12,13)$.

Efficient pure strains of SRB were selected by classical microbiological methods and by mutagenesis (N-methyl-N'-nitro-N-nitrosoguanidine). Some improvement factors have been investigated in 2.5 and $20 \mathrm{~L}$ bench-scale batch bioreactors : stripping, scale-up, sulfate and organic substrate concentrations. 
Two types of continuous pilot-scale bioreactors (completely mixed with free cells and two-stage with immobilized cells on a fixed bed) have been adopted to study feasibility and bioreactor engineering aspects of gypsum reduction. Particular attention was paid to the nature of the organic substrate, association with acidogenic bacteria, immobilization support, retention time and organic inputs.

\section{METHODS}

\section{Media}

Bench-scale experiments used slightly modified culture media B, E and C described by Postgate (3). Medium B (in grams per liter of demineralized water) : $\mathrm{KH}_{2} \mathrm{PO}_{4}, 1 ; \mathrm{MgSO}_{4}$. $7 \mathrm{H}_{2} \mathrm{O}, 2 ; \mathrm{FeSO}_{4} \cdot 7 \mathrm{H}_{2} \mathrm{O}, 0.5 ; \mathrm{CaSO}_{4} \cdot 2 \mathrm{H}_{2} \mathrm{O}, 1 ; \mathrm{NH}_{4} \mathrm{Cl}, 1$; yeast extract, 1 ; ascorbic acid, 0.2 ; sodium thioglycolate, 0.1 ; sodium lactate, 3.5 (for LSRB); sodium acetate trihydrate, 4 (for ASRB). Medium C : $\mathrm{KH}_{2} \mathrm{PO}_{4}, 1 ; \mathrm{MgSO}_{4} \cdot 7 \mathrm{H}_{2} \mathrm{O}, 0.06 ; \mathrm{FeSO}_{4} \cdot 7 \mathrm{H}_{2} \mathrm{O}, 0.004 ; \mathrm{CaSO}_{4} \cdot$ $2 \mathrm{H}_{2} \mathrm{O}, 3.5 ; \mathrm{CaCl}_{2} \cdot 2 \mathrm{H}_{2} \mathrm{O}, 0.02 ; \mathrm{NH}_{4} \mathrm{Cl}, 1$; yeast extract, 1 ; ascorbic acid, 0.2 ; sodium thioglycolate, 0.1; sodium lactate, 6 (for LSRB); sodium acetate trihydrate, 4 (for ASRB). Medium E : $\mathrm{KH}_{2} \mathrm{PO}_{4}, 1 ; \mathrm{MgSO}_{4} \cdot 7 \mathrm{H}_{2} \mathrm{O}, 0.2 ;\left(\mathrm{SO}_{4}\right)_{2} \mathrm{Fe}\left(\mathrm{NH}_{4}\right)_{2}, 0.2 ; \mathrm{Na}_{2} \mathrm{SO}_{4}, 1 ; \mathrm{CaCl}_{2}$. $2 \mathrm{H}_{2} \mathrm{O}, 0.5 ; \mathrm{NH}_{4} \mathrm{Cl}, 1$; yeast extract, 1 ; ascorbic acid, 0.2 ; sodium thioglycolate, 0.1 ; sodium lactate, 3.5 (for LSRB); sodium acetate trihydrate, 4 (for ASRB); resazurin (redox indicator), 0.001; agar, 15. Hydrochloric acid and sodium hydroxide were used to adjust $\mathrm{pH}$. All chemicals were of analytical or extra pure quality and supplied by Merck, Union Chimique Belge or Sigma.

Pilot-scale experiments used industrial gypsum from a fertilizer manufacture (analysis after drying at ambient temperature, in $\% \mathrm{w} / \mathrm{v}: \mathrm{H}_{2} \mathrm{O}, 26-28 ; \mathrm{CaO}, 32-33 ; \mathrm{SO}_{3}, 44-46 ; \mathrm{P}_{2} \mathrm{O}_{5}$, 0.4-0.6; $\mathrm{SiO}_{2}, 1.2-1.4 ; \mathrm{K}_{2} \mathrm{O}, 0.01-0.02 ; \mathrm{Al}_{2} \mathrm{O}_{3}, 0.028 ; \mathrm{Fe}_{2} \mathrm{O}_{3}, 0.017 ; \mathrm{MgO}, 0.008 ; \mathrm{Na}_{2} \mathrm{O}$, 0.05; and impurities in mg/kg : As, 1-7; Cd, 4-13; $\mathrm{Co},<1 ; \mathrm{Cr}, 8 ; \mathrm{Cu}, 9 ; \mathrm{Mn}, 3.8 ; \mathrm{Hg},<0.01$; Mo, 3.2; Ni, 11; Pb, 0.8; Se, 2; Ti, 400-700; V, <0.5; Zn, 15-40; Fe, 120. pH : 2.8-3.5).

The cheese whey used as organic substrate contained $(\% \mathrm{w} / \mathrm{v}): \mathrm{H}_{2} \mathrm{O}, 2-4$; lactose, 70; proteins, 11-12; fats, 1.5; minerals $\left(\mathrm{Cl}^{-}, \mathrm{NO}_{3}^{-}, \mathrm{Na}^{+}, \mathrm{K}^{+}, \mathrm{Ca}^{2+}, \mathrm{NH}_{4}^{+}\right), 9 . \mathrm{pH}$ of a $10 \%$ 
solution in water : 6 .

\section{Strains isolation method}

The Postgate (3) general method for strain isolation was applied to samples of natural (poorly salted or unsalted) environments such as manures (pig, bovine and rabbit), estuary which had been hugely contaminated by gypsum, soil, landfill and water from pond $(16,17)$. The screening for ASRB and LSRB was carried out on the same raw samples.

The many facultative anaerobic contaminants present in samples did not permit pure strains to be obtained after 3 or 4 consecutive repetitions of the isolation procedure. Progressively more selective media had to be adopted : medium E containing $1 \mathrm{~g} / \mathrm{L}$ of zinc sulfate (zinc toxicity should be reduced for SRB by $\mathrm{ZnS}$ precipitation), medium B containing 6,000 USP (United States Pharmacopeial) units / L of polymyxin B sulfate (this antibiotic is usually efficient against enterobacteria), medium E containing $0.8 \mathrm{~g} / \mathrm{L}$ of $\mathrm{Na}_{2} \mathrm{~S} \cdot 9 \mathrm{H}_{2} \mathrm{O}$ but no iron (contaminants are usually sensitive to high concentrations of sulfide). In this case, all colonies should be cultivated in medium B to verify sulfate reduction.

\section{Mutagenesis}

Mutations were induced by the chemical mutagen N-methyl-N'-nitro-Nnitrosoguanidine (NTG). Mutants more efficient at producing sulfide would be able to grow on medium containing a high concentration of selenate, a powerful and specific competitive inhibitor of sulfate reduction due to its structure being analoguous to that of the sulfate ion. Indeed, the enzyme system has some 40 -fold greater affinity for the inhibitor, selenate, than for its natural substrate, sulfate. Consequently, selenate would act against the accumulation of sulfate in the organism, rather than on its actual reduction (3).

Cells of the pure SRB strain (further called wild-type strain) in exponential growth phase were suspended in dilution medium (tween, $2 \mathrm{~g} / \mathrm{L}$; bactopeptone, $1 \mathrm{~g} / \mathrm{L} ; \mathrm{NaCl}, 5 \mathrm{~g} / \mathrm{L}$ of demineralized water). One drop of a saturated NTG solution was added to each $10 \mathrm{ml}$ aliquot of cell suspension. The suspension was distributed in sterile centrifugation vessels and incubated at $30{ }^{\circ} \mathrm{C}$ for different periods of time (ranging from 15 minutes to a few hours). At the end of the incubation time, the suspensions were centrifuged at 10,000 RPM for 15 
minutes.

The supernatant was replaced by sterile dilution medium in which the centrifuged cells were once more suspended and washed twice. Eventually, the centrifuged cells were mixed in a minimum of dilution medium, diluted and inoculated (according to the strain isolation method described above), in two series of medium E test tubes, one with $1 \mathrm{~g} / \mathrm{L}$ of $\mathrm{Na}_{2} \mathrm{SO}_{4}$ and the other with a supplement of $6 \mathrm{~g} / \mathrm{L} \mathrm{Na} 2 \mathrm{SeO}_{4}$.

Colonies of mutant bacteria grew in the solid medium containing selenate. Less than 1 $\%$ of cell survival has been observed on selenate free medium after the action of NTG.

\section{Analytical methods}

Sulfate was determined by the turbidimetric method : sulfate ions are precipitated by barium and the solution turbidity was analyzed by a spectrophotometer at $450 \mathrm{~nm}(18)$.

Sulfide was determined photometrically using the methylene blue method applied to 1 $\mathrm{mL}$ liquid samples which had been collected in $5 \mathrm{~mL}$ of a $2 \%(\mathrm{w} / \mathrm{v}$ in water) zinc acetate solution $(19,20)$. However, when sulfide stripping was performed in bench-scale experiments, zinc sulfide was, once or twice a day, gravimetrically determined after 15 minutes stripping with $70 \% \mathrm{~N}_{2}-30 \% \mathrm{CO}_{2}$ and precipitation in $4 \%$ (w/v in water) zinc acetate solution.

In bench-scale experiments, lactate and acetate were determined with a WATERS 590 HPLC equipped with a SHODEX P1011 precolumn and a SHODEX 1011 ion exchange column at $90{ }^{\circ} \mathrm{C}$. For eluant, $1.5 \mathrm{mM} \mathrm{H}_{3} \mathrm{PO}_{4}$ in water was used at a flow rate of $0.7 \mathrm{~mL} / \mathrm{min}$. Samples were filtered on $0.22 \mu \mathrm{m}$ membranes after substitution of calcium for sodium on DOWEX $50 \mathrm{~W}$ resin. A WATERS 410 refractive index detector and a WATERS MODULE 745 integrator were used.

In pilot-scale experiments, carbohydrates (sugars, polysaccharides and oligosaccharides) were photometrically determined at $485 \mathrm{~nm}$ after reaction with phenol in presence of sulfuric acid (21).

Dissolved Organic Carbon (DOC) was photometrically determined : the sample was acidified then stripped by oxygen to remove inorganic carbon; hydroxyl free radicals were 
formed from potassium persulfate by UV irradiation and were reacted with the sample organic carbon to form $\mathrm{CO}_{2}$ and water. The $\mathrm{CO}_{2}$ diffused through a membrane to a phenolphthalein solution, the absorbance of which was measured at $550 \mathrm{~nm}$. Hydroxylamine was used to prevent interference due to the chlorinated compounds contained in the samples (22).

Volatile Fatty Acids (VFA) were determined with a MERCK-HITACHI HPLC (Pump : L-6000, UV-Visible detector at $210 \mathrm{~nm}:$ L-4200, column thermostat : T-6300) equipped with a SUPELCOGEL GL-C610h-SP column operating at $20{ }^{\circ} \mathrm{C}$. For eluant, $10 \mathrm{mM} \mathrm{H}_{3} \mathrm{PO}_{4}$ in water was used at a flow rate of $0.5 \mathrm{~mL} / \mathrm{min}$.

\section{Bench-scale bioreactors}

A 2.5 L glass vessel (2L BIBBY culture vessel) with a stainless steel lid equipped with septum, shaft with 2 Rushton turbines (4 blades, height $10 \mathrm{~mm}$, diameter $45 \mathrm{~mm}$ ), $0.45 \mu \mathrm{m}$ gas filters and tubings for sampling, gas inlet, gas outlet and temperature regulation was used as the bench-scale bioreactor (constructed at University of Liege). Medium C (2 L) was autoclaved at $120{ }^{\circ} \mathrm{C}$ for 20 minutes, cooled under nitrogen and inoculated with $250 \mathrm{ml}$ of cell culture in medium B.

A 20 L full stainless steel LSL BIOLAFITTE SA fermenter equipped with $\mathrm{pH}$ regulation, shaft with 3 Rushton turbines (4 blades, height $20 \mathrm{~mm}$, diameter $100 \mathrm{~mm}$ ), gas filters, septum and tubings as in the small bioreactor was used to study the scale-up improvement factor. A volume of $12 \mathrm{~L}$ of medium $\mathrm{C}$ was sterilized (by steam at $120{ }^{\circ} \mathrm{C}$ ) in the fermenter, cooled under nitrogen and inoculated with $2 \mathrm{~L}$ of cell culture in medium B.

Needles placed through the septum were used to maintain pH (INGOLD combined probe) in the range $7.15-7.35$ (the probe deviation due to sulfide was taken into account) by means of sterile $\mathrm{HCl}(3 \mathrm{~N})$ or $\mathrm{NaOH}(3 \mathrm{~N})$ addition. Redox-poising agents like thioglycolate or ascorbic acid were added during inoculation to prevent their degradation by oxygen during cooling. The stirring speed and temperature were kept constant at about $100 \mathrm{RPM}$ and $30{ }^{\circ} \mathrm{C}$, respectively. The redox potential of samples was determined with an INGOLD Platinum combined probe. During culture, the bioreactors were overpressurized by about 0.1 bar. 


\section{Pilot-scale bioreactors}

The fixed-bed pilot-scale set-up is shown in figure 1. In both reactors (constructed with stainless steel), the biologically active volume was $30 \mathrm{~L}$. The reactors contained a solid support matrix (Plasdek type, PVC material, $97 \%$ internal porosity, $50 \mathrm{~kg} / \mathrm{m}^{3}$ density, 157 $\mathrm{m}^{2} / \mathrm{m}^{3}$ specific area). Gypsum and cheese whey inputs have been progressively increased (in the first stage) from $6.5 \mathrm{~kg} / \mathrm{m}^{3}$. d of industrial gypsum and $3 \mathrm{~kg} / \mathrm{m}^{3}$. d of whey to 18 and 8.5 $\mathrm{kg} / \mathrm{m}^{3} . \mathrm{d}$, respectively. The medium (gypsum and whey in water) was continuously pumped from the bottom to the top of both columns. Sulfide was continuously stripped by nitrogen gas (at a $40 \mathrm{~L} / \mathrm{h}$ frow rate) and absorbed in a sodium hydroxide $(7.5 \mathrm{~N}$ in water) solution.

The first stage was inoculated with sediments obtained from the Seine estuary and worked discontinuously (no whey nor gypsum input or output) for a few weeks in order to improve immobilization of the bacteria. After this period, it was continuously operated at a hydraulic retention time of 6 days.

The second stage was inoculated with the wild-type ASRB strain which had been investigated in bench-scale experiments. The culture medium was directly transferred from the first stage, however, in the second stage, the retention time was 12 days (twice that of the first stage).

The mixed pilot-scale set-up was similar to the former but featured only one stage (constructed with stainless steel). The biologically active volume was $30 \mathrm{~L}$, the stirring speed was 120 RPM and the hydraulic retention time was 10 days. Industrial gypsum and cheese whey inputs have been progressively increased from $0.85 \mathrm{~kg} / \mathrm{m}^{3}$. $\mathrm{d}$ and $3.5 \mathrm{~kg} / \mathrm{m}^{3}$. $\mathrm{d}$ to 13 $\mathrm{kg} / \mathrm{m}^{3}$. $\mathrm{d}$ and $43.5 \mathrm{~kg} / \mathrm{m}^{3}$. d, respectively. The medium was also continuously pumped (at a $2,000 \mathrm{~L} / \mathrm{h}$ flow rate) from the bottom to the top of the bioreactor and sulfide was continuously stripped by nitrogen gas (at a $40 \mathrm{~L} / \mathrm{h}$ flow rate). The inoculum was also made of sediments obtained from the Seine estuary.

In both pilot-scale set-ups, temperature was maintained at $35^{\circ} \mathrm{C}, \mathrm{pH}$ between 6 and 8 and redox potential between $-140 \mathrm{mV}$ and $-240 \mathrm{mV}$. 


\section{RESULTS}

\section{Selection of SRB strains}

The selection of SRB strains from natural samples provided one ASRB strain purified from rabbit manure and 4 LSRB strains purified from bovine manure, soil, Seine estuary (France) and water from pond. All 5 strains were studied in $2.5 \mathrm{~L}$ bioreactors (conditions described in Methods).

At the end of bioconversion (i.e. after about 150 hours), the ASRB strain induced sulfide concentration of $66.6 \mathrm{mg} \mathrm{S} \mathrm{S}^{2-} / \mathrm{L}$; and the LSRB induced $218 \mathrm{mg} \mathrm{S}^{2-} / \mathrm{L}$ for bovine

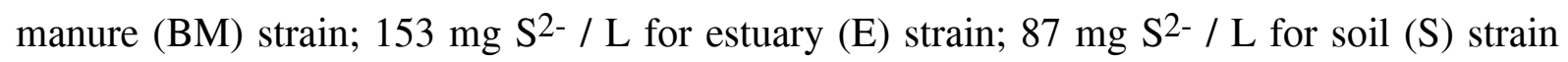
and too weak a value, to be correctly measured, for water from pond (W) strain. Moreover, the $\mathrm{BM}$ and $\mathrm{E}$ strains had regularly consumed the $5.5 \mathrm{~g} / \mathrm{L}$ of sodium lactate during the \pm 150 hours of culture.

As illustrated in figure 2, plots for wild-type strain and mutant displayed different patterns depending on the organic substrate and the selection type. Therefore, results should also mention maximum sulfate reduction yield, calculated in industrial gypsum equivalent $\left(\mathrm{CaSO}_{4} \cdot 2 \mathrm{H}_{2} \mathrm{O}+30 \%\right.$ free water), as in pilot-scale results. Therefore BM strain daily reduced, at its maximum exponential phase, $470 \mathrm{~g}$ of raw industrial gypsum equivalent per cubic meter of culture medium; E, $217 \mathrm{~g} / \mathrm{m}^{3} . \mathrm{d} ; \mathrm{S}, 238 \mathrm{~g} / \mathrm{m}^{3} . \mathrm{d}$ and the ASRB strain, 127 $\mathrm{g} / \mathrm{m}^{3} \cdot \mathrm{d}$.

\section{Improvement of sulfide production in bench-scale bioreactors}

The most productive, ASRB and BM, of both organic substrates oxidizing strains were investigated to determine which improvement factors could influence sulfide production and sulfate reduction yield.

For ASRB, the factors studied were : temperature (from 30 to $38^{\circ} \mathrm{C}$ ), the concentration of gypsum and acetate in medium (medium $\mathrm{C}: 3.5$ and $4 \mathrm{~g} / \mathrm{L}$, respectively; rich medium : 7.5 and $8 \mathrm{~g} / \mathrm{L}$ ) and mutagenesis.

For LSRB, the improvement factors studied were : the sulfide stripping (i.e. sulfide removing from culture medium by means of a nitrogen flow as described above), the scale-up 
(from 2.5 to 20 L bioreactor), the concentration of gypsum and lactate in medium (medium C : 3.5 and $6 \mathrm{~g} / \mathrm{L}$ respectively; rich medium : 10 and $10 \mathrm{~g} / \mathrm{L}$ ) and mutagenesis.

The results are given in table 1 which shows the maximum sulfide concentration induced in the culture medium (mg $\mathrm{S}^{2-} / \mathrm{L}$; in case of stripping, it has no meaning) and the maximum sulfate reduction yield ( $\mathrm{kg}$ of industrial gypsum daily reduced per cubic meter of medium). Figure 3 shows the sulfate reduction yields obtained with both SRB types under various conditions of culture.

\section{Pilot-scale experiments}

Different raw organic substrates were used, such as sugar-refinery molasses, cheese whey and the mixture of cheese whey and methanol in various proportions (ratio methanol:lactose in weight being 1:1; 3:1 and 9:1). Best results, especially in terms of DOC in effluent, have been obtained with cheese whey.

In the single-stage mixed bioreactor, at a $6.2 \mathrm{~kg} / \mathrm{m}^{3}$. d gypsum input, a yield of 5.5 $\mathrm{kg} / \mathrm{m}^{3}$. $\mathrm{d}$ of gypsum reduction was observed (i.e. $90 \%$ of the gypsum fed, related to $85 \%$ of DOC degradation). A better gypsum reduction yield was obtained at a $13 \mathrm{~kg} / \mathrm{m}^{3}$. d gypsum input : $7.8 \mathrm{~kg} / \mathrm{m}^{3}$. $\mathrm{d}$ of gypsum reduction (i.e. only $60 \%$ of the gypsum supplied, related to 38 $\%$ of DOC degradation).

With regard to the fixed-bed bioreactor, at a $18 \mathrm{~kg} / \mathrm{m}^{3}$. d gypsum input, the gypsum reduction yield reached $11 \mathrm{~kg} / \mathrm{m}^{3}$. d (i.e. $60 \%$ of the gypsum fed). At this yield, $1.2 \mathrm{~kg} / \mathrm{m}^{3} . \mathrm{d}$ of DOC was oxidized, which means $45 \%$ of the DOC fed. However, during biomass growth and immobilization, a higher DOC degradation yield of 55\% was observed. It must be emphasized that a DOC conversion inferior or equal to $40 \%$ was attributed to lactic acid oxidation.

The important DOC concentration in the first stage output is constituted primarily (16 $\mathrm{g} / \mathrm{L}$ ) of acetic acid, which was poorly oxidized. These results show the benefit of working with two stages, reducing organic carbon concentration in effluent and also increasing gypsum reduction yield.

It should be mentioned that, at such high inputs, $\mathrm{pH}$ is not easily stabilized; higher 
inputs lead to bioconversion breakdown. Thus it seems that there is an input limit of organic substrate which can not be exceeded without risk of serious acidification and growth inhibition.

Part of the effluent of the first stage, which contained primarily acetic acid, was transferred to the second reactor. Thus the concentration of gypsum and organic substrate available for ASRB was progressively increased in the second stage. At the highest gypsum input $\left(3.3 \mathrm{~kg} / \mathrm{m}^{3}\right.$. d), $3 \mathrm{~kg} / \mathrm{m}^{3}$. d of industrial gypsum were reduced (i.e. $90 \%$ of the gypsum supplied in the second stage) and DOC conversion reached $0.25 \mathrm{~kg} / \mathrm{m}^{3}$. d (35\% of DOC fed in the second stage). Therefore, an overall degradation of $65 \%$ of the DOC main input was achieved.

\section{DISCUSSION}

\section{Bench-scale experiments}

Bench-scale experiments realized with pure strains of bacteria have revealed some improvement factors which could increase the gypsum bioconversion yield. The results of figure 3 emphasize the important improvement carried out by the mutation of both SRB types. Indeed, for ASRB, the improvement factors (i.e. the ratios of the maximum sulfate reduction yield carried out by the mutant to that carried out by the wild-type strain) on medium $\mathrm{C}$ and on the rich medium are 3.54 and 3.9, respectively. For LSRB, the improvement factors on medium $\mathrm{C}$, without stripping and with stripping of hydrogen sulfide, are 1.58 and 1.61 , respectively.

Although improvement carried out by the mutation is greater for ASRB, it should be noted that, with the wild-type strain, sulfide concentration inside the bioreactor follows a linear, rather than exponential, course indicating a lower yield (the patterns obtained at $38{ }^{\circ} \mathrm{C}$ and in rich medium are similar to that shown in figure 2).

Hauser (23) and Postgate (3) suggest that non-exponential growth of SRB cultures may be attributed to the loss of readily available iron (essential for SRB) from solution, particularly when it is precipitated by sulfide. Further investigations are required to explain 
the beneficial influence of the bacterial mutations, one possible explanation could be an improved production of iron chelating agent(s), a higher rate of incorporation of iron into the cell or a lower requirement for iron.

The production of iron chelating agents has been postulated by Hauser (23). Under conditions where the dissolved iron concentration is very low, SRB would produce highly specific chelating agents (more powerful than citrate contained in medium C) which could be released into solution or located on the cell surface, this hypothesis is suggested by tactophily (tendency to adhere to surfaces often observed in freshly isolated culture of SRB (3)).

The rate of incorporation of iron and the requirement of metabolism for iron depend, amongst other things, on electron carriers. The most common electron carriers in SRB are cytochromes, ferredoxins, rubredoxins and flavodoxins $(3,13)$. These proteins do not have an identical iron amount, nor well-known roles in each of the SRB strains. Furthermore, some carriers, such as flavodoxin and ferredoxin, when they are both present in the cell, may replace each other (13). These are some factors on which mutations might have operate to improve ASRB bioconversion.

In bioconversions with LSRB, the steady state was obtained following the complete exhaustion of lactate. The maximum sulfide concentration was reached at approximately 870 $\mathrm{mg} / \mathrm{L} \mathrm{S}^{2-}$. The relative distribution of $\mathrm{H}_{2} \mathrm{~S}$ and $\mathrm{HS}^{-}$at $\mathrm{pH} 7.25$ (mean of the $\mathrm{pH}$ regulation range; $\mathrm{pK}_{\mathrm{a}}$ of $\mathrm{H}_{2} \mathrm{~S}$ is 7.0 at $25^{\circ} \mathrm{C}$ ) is about $1: 1.78$. Therefore, the steady state concentration of free $\mathrm{H}_{2} \mathrm{~S}$ did not exceed $330 \mathrm{mg} / \mathrm{L}$. The mean concentration of $\mathrm{H}_{2} \mathrm{~S}$ is not far below its toxic level (i.e. $550 \mathrm{mg} / \mathrm{L}, 6,24$ ). This means that further improvement factors should be investigated with gas stripping at each stage to avoid limitations caused by $\mathrm{H}_{2} \mathrm{~S}$ toxicity.

Summarizing the results of the laboratory experiments, it can be concluded that a gypsum reduction higher than $10 \mathrm{~kg} / \mathrm{m}^{3}$. $\mathrm{d}$ is easily achievable if all the improvement factors are combined with each other (sulfide stripping, $38{ }^{\circ} \mathrm{C}$ instead of $30{ }^{\circ} \mathrm{C}$, a more concentrated medium of gypsum and organic substrate, mutagenesis and scale-up). A gypsum reduction yield above $10 \mathrm{~kg} / \mathrm{m}^{3}$. d was eventually reached in pilot-scale bioreactor without mutant biomass. 
However, bioconversion with ASRB is still not satisfactory. Mutations have induced a lower reliance on iron but the steady state is rapidly attained, at a time when all organic substrate has not been consumed.

Further experiments will be performed to explain the reasons for this inhibition, possible causes include $\mathrm{H}_{2} \mathrm{~S}$ inhibition or lack of vitamins. We will also try to obtain other ASRB strains.

\section{Pilot-scale experiments}

Experiments realized in mixed bioreactor have shown that gypsum reduction yield increases as a function of sulfate concentration, reaching $7.8 \mathrm{~kg} / \mathrm{m}^{3} . \mathrm{d}$ at an industrial gypsum concentration of about $50 \mathrm{~g} / \mathrm{L}$ (that is, when $40 \%$ of the $13 \mathrm{~kg} / \mathrm{m}^{3}$. d of gypsum input is not converted). However, it is important to mention that gypsum is only soluble in water at about $1 \mathrm{~g} / \mathrm{L}$. Therefore a great deal of solid matter is present in the culture medium. Thus, the presence of solid is probably one of the reasons contributing to observed phenomenon, it would act as an immobilization support.

Nevertheless, the gypsum input should not exceed $6.5 \mathrm{~kg} / \mathrm{m}^{3} . \mathrm{d}$ because the converted fraction of gypsum begins to decrease rapidly below $90 \%$ and acetate tends to accumulate, creating effluent of high DOC (another fundamental problem that is to be solve).

We have partly resolved this issue in the fixed-bed set-up : a second stage is joined to the main bioreactor in order to enhance acetate oxidation. The conditions (mainly the hydraulic retention time) are modified to allow better development of ASRB.

On the whole, the first stage works at a high sulfate reduction yield $\left(11 \mathrm{~kg} / \mathrm{m}^{3} . \mathrm{d}\right.$ of industrial gypsum) while output effluent still contains about $40 \%$ of the gypsum fed. This gypsum will finally be reduced in the second stage by ASRB which, in addition, will oxidize the acetate produced by the LSRB in the first stage. Analyzing the results obtained in the second stage, it must be noted that gypsum concentration should be raised again since near total gypsum reduction is obtained while acetate remains (35\% of the DOC supplied, that is, $5.5 \mathrm{~g} / \mathrm{L}$ of COD).

Our results also clearly demonstrate that the association of acidogenic and sulfate- 
reducing bacteria is relatively efficient in a sole reactor, as already mentioned by Salmon (15).

Further experiments at the pilot scale will determine the most convenient type of bioreactor to carry out gypsum bioconversion at industrial-scale. In these experiments, a more sophisticated set-up will be assessed, including an evaluation of the number of stages, the use of mutants at each step and the influence of carbonate production on cell immobilization and on support.

\section{ACKNOWLEDGEMENTS}

This work was supported by a European Community grant (Reward CT90004). S Hiligsmann is recipient of a FRIA fellowship (Fonds de la communauté française de Belgique pour la Formation à la Recherche dans l'Industrie et l'Agriculture).

\section{REFERENCES}

1. Savostianoff, D. (1990), Informations Chimie 314, 131-151.

2. Jørgensen, B. (1982), in Microbial Geochemistry, Krumbein, W. E., ed., Blackwell Scientific Publications, Oxford, pp. 91-119.

3. Postgate, J. R. (1984), The sulfate-reducing bacteria, Cambridge University Press, London.

4. Winter, G., Büchner, W., Schliebs, R. and Büchel, K. H. (1989), Industrial inorganic chemistry, VCH, Weinheim/Germany.

5. Cork, D. J. and Cusanovich, M. A. (1978), Dev. Ind.Microbiol. 20, 591-602.

6. Vanhouten, R. T., Pol, L. W. H. and Lettinga, G. (1994), Biotech. and Bioeng. 44, 586594.

7. Hilton, B. L. and Oleszkiewicz, J. A. (1987), 41st Purdue University Industrial Waste Conference Proceedings, 156-166.

8. Uphaus, R. A., Grimm, D. and Cork, D. J. (1983), Dev. Ind.Microbiol. 24, 435-442.

9. Burgess, S. B. and Wood, L. B. (1961), J. Sci. Food Agr. 12, 326-334. 
10. Maree, J. P., Hulse, G., Dods, D. and Schutte, C. E. (1991),Wat. Sci. Tech. 23, 12931300.

11. Milande, N., Deswaef, S., Crine, M., Taillieu, X., Hiligsmann, S. and Thonart, Ph. (1993), Report of the European Community REWARD-Project CT 90004.

12. Widdel, F. and Bak, F. (1991), in The prokaryotes, Balows, A., Trüper, H. G., Dworkin, M., Harder, W. and Schleifer, K. H., eds., Springer-Verlag, Berlin, vol. 4, pp. 3352-3378.

13. Widdel, F. and Hansen, T. A. (1991), in The prokaryotes, Balows, A., Trüper, H. G., Dworkin, M., Harder, W. and Schleifer, K. H., eds., Springer-Verlag, Berlin, vol. 1, pp. $583-624$.

14. Widdel, F. (1991), in The prokaryotes, Balows, A., Trüper, H. G., Dworkin, M., Harder, W. and Schleifer, K. H., eds., Springer-Verlag, Berlin, vol. 2, pp. 1793-1799.

15. Salmon, T., Schlitz, M. and Crine, M. (1990), Asia-Pacific Biochemical Engineering conference, Kyungja/Korea, 292-295.

16. Gibson, G. R. (1990), J. Appl. Bacteriol. 69, 769-797.

17. Widdel, F. and Pfennig, N. (1984), in Bergey's manual of systematic bacteriology, Krieg, N. R. and Holt, J. G., eds., Williams and Wilkins, Baltimore/London, vol. 1, pp. 663679.

18. Greenberg, A. E., Trussell, R. R. and Clesceri, L. S. (1985), Standard methods for the examination of water and wastewater, APHA-AWWA-WPCF, Washington.

19. Fogo, J. K. and Popowsky, M. (1949), Anal .Chem. 21, 732-734.

20. Florin, T. H. J. (1991), Clinica Chimica Acta 196, 127-134.

21. Liu, D., Wong, P. T. S. and Dutka, D. J. (1973), Wat. Research 7, 741-746.

22. Schreurs, W. (1978), Hydrological Bulletin 12, 137-142.

23. Hauser, J. Y. and Holder, G. A. (1986), Biotech. and Bioeng. 28, 101-106.

24. Reis, M. A., Almeida, J. S., Lemos, P. C. and Carrondo, M. J. T. (1992), Biotech. and Bioeng. 40, 593-600. 


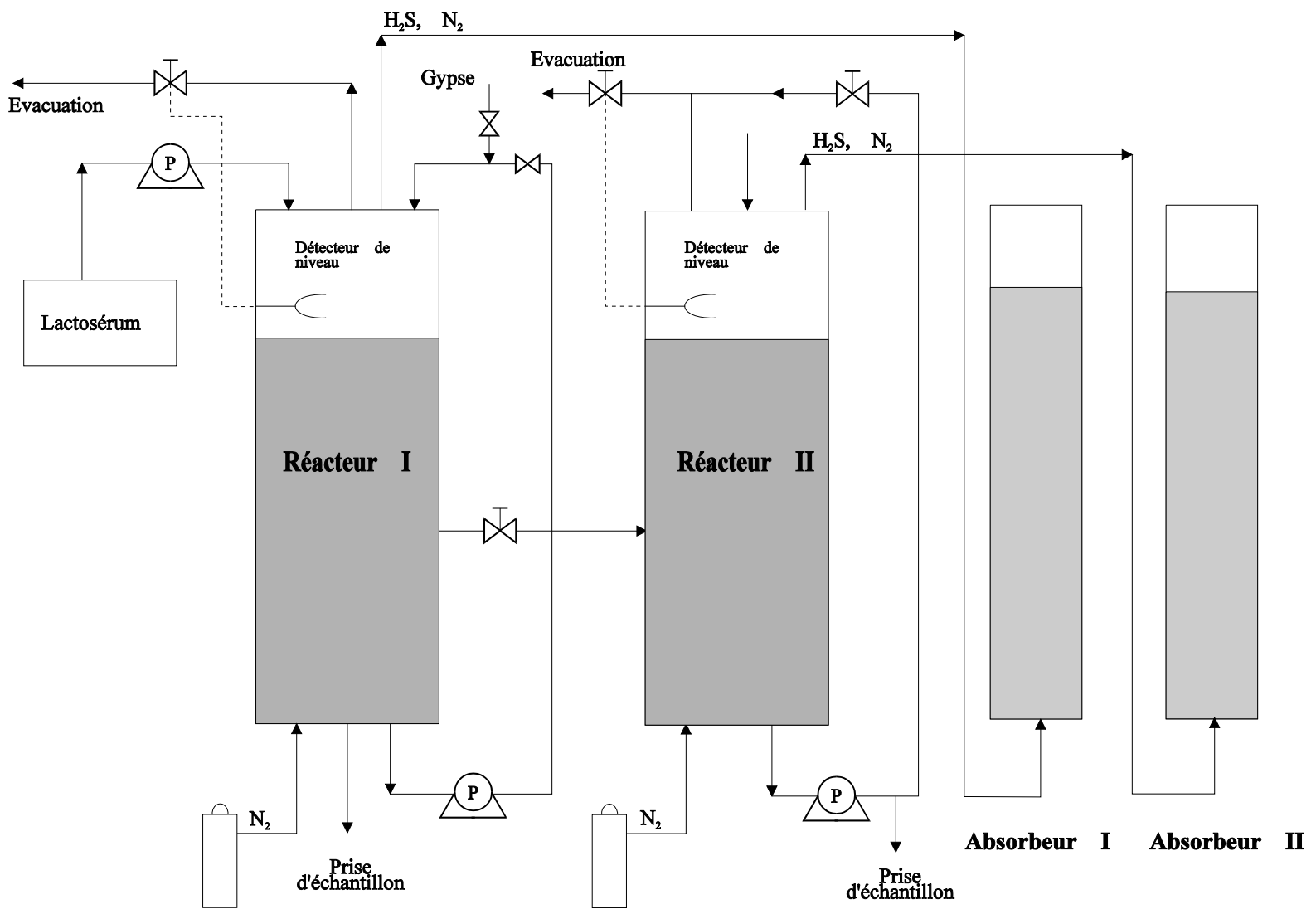

Figure 1. Flow sheet of the fixed-bed pilot-scale set-up. 
Table 1

Results of the investigation of some improvement factors for acetate-(ASRB) and lactate(LSRB) oxidizing sulfate-reducing bacteria strains. Maximum sulfide concentration reached in the culture medium and maximum sulfate reduction yield are given.

\begin{tabular}{cccccc}
\hline \multirow{2}{*}{ ASRB } & \multicolumn{2}{c}{ Wild-type strain } & & \multicolumn{2}{c}{ Mutant } \\
\cline { 2 - 3 } \cline { 5 - 6 } & $38^{\circ} \mathrm{C}$ & rich medium & & medium C & rich medium \\
\hline $\begin{array}{c}\text { Maximum sulfide concentration } \\
\left(\mathrm{S}^{2-} \mathrm{mg} / \mathrm{L}\right)\end{array}$ & 85.5 & 95 & & 101 & 90 \\
Maximum sulfate reduction & 0.329 & 0.400 & & 0.450 & 1.56 \\
yield & & & & \\
(industrial gypsum $\left.\mathrm{kg} / \mathrm{m}^{3} . \mathrm{d}\right)$ & & & & & \\
\hline
\end{tabular}

\begin{tabular}{|c|c|c|c|c|c|}
\hline \multirow[t]{2}{*}{ LSRB } & \multicolumn{2}{|c|}{ Wild-type strain } & \multicolumn{3}{|c|}{ Mutant } \\
\hline & stripping & scale-up & medium $\mathrm{C}$ & $\begin{array}{c}\text { rich } \\
\text { mediun }\end{array}$ & stripping \\
\hline $\begin{array}{l}\text { Max. sulfide concentration } \\
\qquad\left(\mathrm{S}^{2-} \mathrm{mg} / \mathrm{L}\right)\end{array}$ & $\mathrm{NM}^{\mathrm{a}}$ & 450 & 731 & 871 & $\mathrm{NM}^{\mathrm{a}}$ \\
\hline $\begin{array}{l}\text { Max. sulfate reduction yield } \\
\text { (industrial gypsum } \mathrm{kg} / \mathrm{m}^{3} . \mathrm{d} \text { ) }\end{array}$ & 1.2 & 4.07 & 0.743 & 1.47 & 1.93 \\
\hline
\end{tabular}

a No meaning because the stripping removes the hydrogen sulfide from the culture medium. 

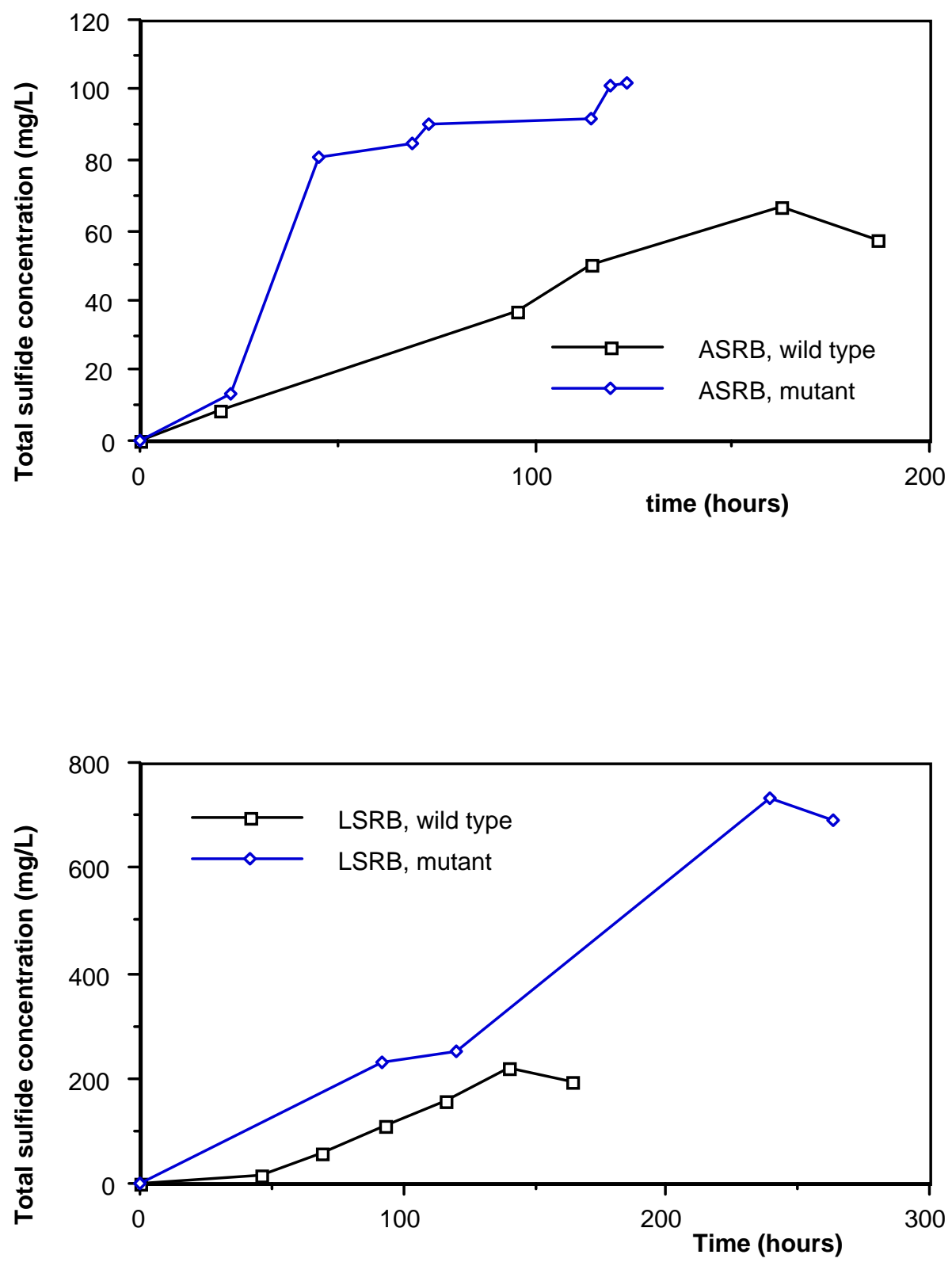

Figure 2. Total sulfide concentration $\left(\mathrm{mg} \mathrm{S}^{2-} / \mathrm{L}\right)$ in the culture medium $\mathrm{C}$ during $2.5 \mathrm{~L}$ batch cultures with acetate-(ASRB) and lactate-(LSRB) oxidizing sulfate-reducing bacteria strains, before (wild type) and after mutagenesis. 

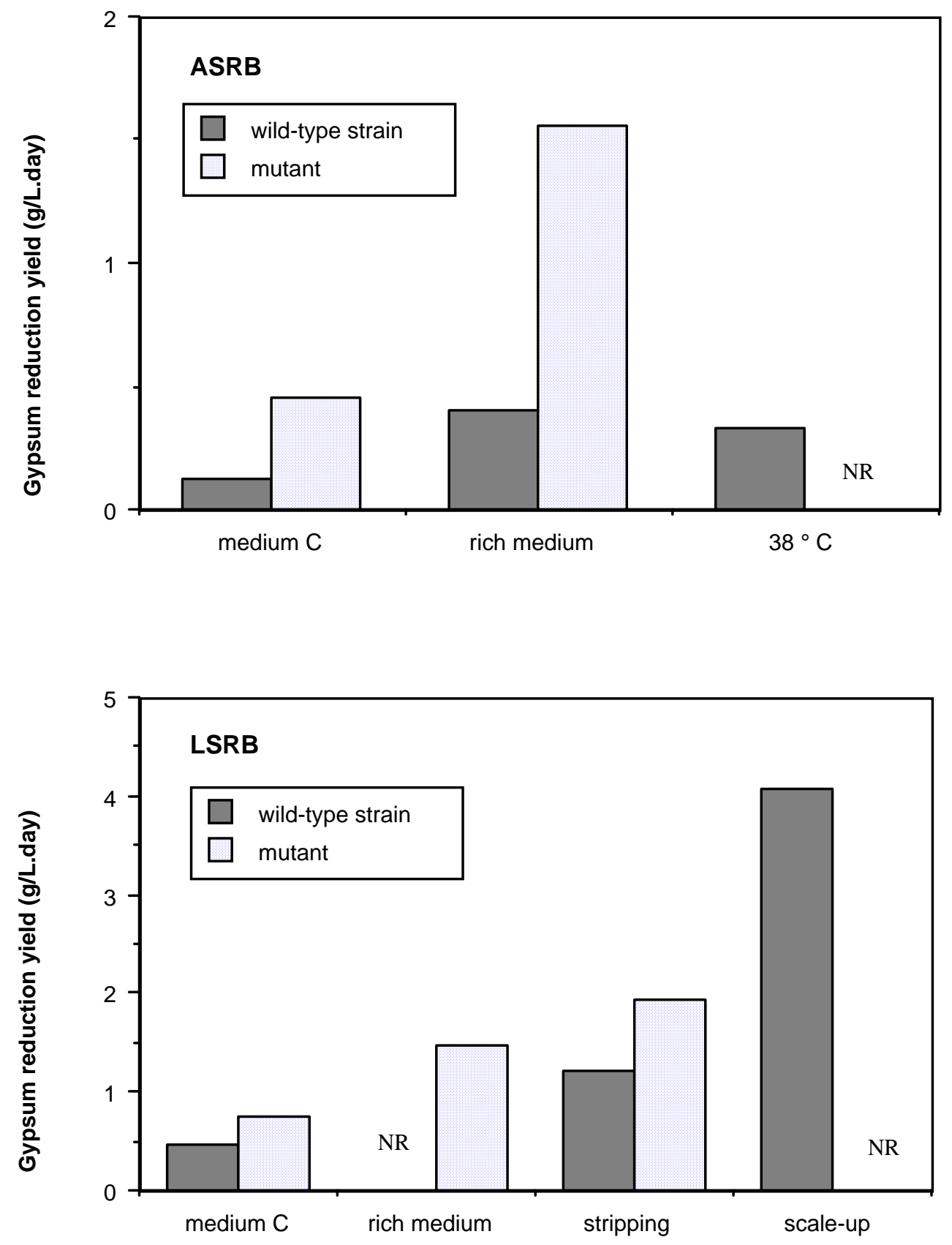

Figure 3. Maximum sulfate reduction yields obtained in various batch culture conditions with acetate-(ASRB) and lactate-(LSRB) oxidizing sulfate-reducing bacteria strains, before (wild-type strain) and after mutagenesis. NR means not realized. 